\title{
VALUATION APLICADO AO SETOR DE EDUCAÇÃO DE ENSINO SUPERIOR POR FLUXO DE CAIXA DESCONTADO
}

\author{
José Eduardo Zdanowicz' \\ Daniel Knebel Baggio² \\ Guilherme Batista ${ }^{3}$
}

\section{Resumo}

O presente estudo tem como objetivo realizar o valuation de duas empresas de capital aberto do setor de Educação Superior no Brasil: Anhanguera Educacional Participações S/A e Kroton Educacional S/A. O método utilizado para se alcançar o objetivo proposto foi o de fluxo de caixa descontado que corresponde em projetar o caixa futuro, encontrar a taxa de desconto para o fluxo de caixa projetado, visando chegar ao valor justo da empresa. O Período de análise corresponde os anos de 2010 a 2014. Por fim, os resultados financeiros demonstraram que probabilidade é de que a empresa Kroton Educacional S/A obtenha vantagem quanto a risco/retorno, tendo isto em vista a indicação de investimento foi para a mesma.

Palavras chave: Valuation; Fluxo de caixa descontado; Avaliação; Contabilidade

Classificação JEL: G1; G11

Doutorado em Administração e Gestão Empresarial pela Universidad de León - Espanha. Tem experiência nas áreas de Administração, Contabilidade e Economia com ênfase em Custos, Finanças, Controladoria, Orçamento, Gestão de Pessoas e Governança: familiar, corporativa e cooperativa. E-mail: profeduardoz@hotmail.com

2 Doutorado em Contabilidade e Finanças - Universidad de Zaragoza. Professor do Programa de Pós-Graduação em Desenvolvimento da UNIJUI. Investigador pela Universidad de Zaragoza, integrando o Grupo de Investigación en Economia Financiera (GIECOFIN). E-mail: baggiod@unijui.edu.br

3 MBA em Finanças e Mercado de Capitais pela Universidade Regional do Noroeste do Estado do Rio Grande do Sul - UNIJUÍ e atualmente está cursando Mestrado em Desenvolvimento também pela Universidade Regional do Noroeste do Estado do Rio Grande do Sul - UNIJUÍ. E-mail: guile_batista@yahoo.com.br 


\section{INTRODUÇÃO}

Manter constante análise dos dados e demonstrações financeiras é de extrema importância em momentos de relevância para a empresa como em fusões, aquisições, dissoluções de sociedade e avaliação de seus gestores. As companhias que fazem de forma constante a gestão de valor estimado com foco na melhoria do mesmo tendem a obter mais expressão no mercado. (ZDANOWICZ, 2012).

Para se chegar a estás informações, existem diversas formas de se calcular o valor financeiro de uma empresa, tais como: avaliação baseada em ativos; avaliação relativo-comparativa; avaliação baseada em fluxo de caixa entre outros.

A palavra valuation tem origem no mercado financeiro e significa avaliação de empresas. Na administração financeira, o valuation, é o processo utilizado para apurar o valor de uma determinada instituição, ativo, ou máquina que tenha como objetivo exercer alguma atividade econômica. (PÓVOA, 2007).

Neste viés o objetivo deste estudo é realizar o valuation de duas empresas de capital aberto do setor de Educação Superior no Brasil: Anhanguera Educacional Participações S/A e Kroton Educacional S/A. Elas correspondem as duas maiores empresas do ramo educacional do Brasil.

A análise financeira das mesmas visou gerar informações para possíveis investidores sobre as instituições e o cenário educacional que atuam, pois há uma carência na literatura sobre o setor.

Para tanto, buscou-se compreender se estas companhias têm potencial de valorização no longo prazo, e se confirmada esta hipótese, qual das duas seria a melhor oportunidade de investimento no que se refere ao retorno sobre o capital investido?

O presente artigo se estrutura da seguinte maneira: seguidamente será apresentado o referencial teórico que subsidiará este estudo. Em um próximo momento a metodologia e os resultados, nas seções 3 e 4, do presente artigo. Por fim as considerações finais na seção 5. 


\section{REFERENCIAL TEÓRICO}

No referencial teórico, são abordados os conceitos que possibilitam uma maior compreensão sobre a avaliação de empresas, suas aplicações e objetivos para investidores e instituições.

Inicialmente realiza-se uma caracterização das duas empresas estudadas e seguidamente serão apresentados os diferentes métodos de avaliação de empresas, com enfoque central no método de fluxo de caixa descontado.

\subsection{Caracterização das empresas}

\subsubsection{Anhanguera Educacional}

A Anhanguera Educacional Participações S/A, é uma das maiores instituições de ensino em número de alunos, bem como uma das maiores empresas de capital aberto do setor de educação, em termos de valor de mercado.

A Companhia tem 490 mil alunos, distribuídos em seus 70 campus e mais de 500 pólos. Ela está presente em todos os estados brasileiros e no Distrito Federal. Atualmente, o valor de mercado da Companhia, é de R\$ 7,03 bilhões, com base no preço de negociação das ações no encerramento do pregão da BM\&FBOVESPA na data de 30 de junho de 2014.

\subsubsection{Kroton Educacional S/A}

A Kroton Educacional S/A também corresponde a uma das maiores organizações educacionais privadas do Brasil, com uma trajetória de mais de 45 anos na prestação de serviços no Ensino Básico e mais de 10 anos no Ensino Superior.

Em 2010, a Kroton adquiriu o Grupo IUNI Educacional, Instituição que também atuava no segmento de cursos de Graduação e pós-graduação. O destaque foi à aquisição da Universidade Norte do Paraná (Unopar), a maior instituição de Educação à Distância do país. 
Em 2012, a Kroton também adquiriu o Grupo Uniasselvi, que possuía atuação tanto no Ensino Presencial quanto na Educação à Distância, consolidando assim a liderança da Kroton na Educação a Distância no Brasil.

Atualmente, a Kroton possui 53 unidades de Ensino Superior, presentes em 10 estados e 39 cidades brasileiras e 447 pólos de Graduação EAD credenciados pelo Ministério da Educação. A Companhia ainda conta com mais de 810 escolas associadas em todo o território nacional, além de cinco no Japão e uma no Canadá, por meio da Rede Pitágoras.

\subsection{Considerações gerais de avaliação de empresas}

A análise de empresa deve avaliar de forma criteriosa, os aspectos pertinentes quanto às disponibilidades financeiras e à capacidade de gerar lucro da instituição. Segundo Zdanowicz (2012, p. 67), "a partir das Demonstrações Financeiras, pode ser realizada uma série de análises financeiras pelo enfoque gerencial, visando avaliar analiticamente o comportamento da organização". O que se percebe é que o autor enfoca que a avaliação da empresa deve ser realizada por diversos pontos para se chegar a uma estimativa mais confiável, aspectos como liquidez e solvência, visando observar os problemas potencias que as instituições podem vir a sofrer, cenário econômico, capacidade de inovação, capacidade de geração de riqueza, observando a receita obtida exclusivamente de seus produtos oferecidos entre outros. Para Zdanowicz (2012, p. 67); "é importante destacar que a análise financeira gerencial não pode limitar-se apenas aos indicadores de natureza interna, pois há fatores que impactam na organização que se originam no âmbito externo, por exemplo, a evolução das taxas de inflação, de juros e câmbio no setor".

Para tanto se deve observar diversos fatores, com o intuito de se chegar a uma estimativa mais assertiva sobre, os fatores internos e externos das empresas estudadas.

\subsubsection{Conceitos de avaliação de empresas}

Os conceitos básicos, referentes aos fundamentos de métodos de avaliação de empresas, servem para dar maior clareza ao estado atual das ins- 
tituições. Para Titman e Martins (2010, p. 82); "a escolha deve considerar o propósito da avaliação e as características próprias do empreendimento. Os modelos são classificados em técnicas comparativas de mercado, técnicas baseadas em ativos e passivos ajustados e baseados no desconto de fluxos futuros de benefícios".

Assim, utilizou-se o método de fluxo de caixa descontado, pois Copeland, Koller e Murrin (2002) argumentam que a análise por fluxo de caixa descontado é a mais confiável. Os mesmos ressaltam que uma avaliação por lucros contábeis pode sofrer manipulações de resultado. Ainda, na avaliação por múltiplos, só teria assertividade, se as empresas avaliadas tivessem estruturas de custos e receitas equivalentes.

Segundo Póvoa (2007, p. 11), “o que mais intriga a avaliação de ativos, ou no valuation, é que não existe resposta ou metodologia que pode ser considerada como única correta". O autor expressa que o importante realmente é que através da aplicação de uma teoria específica ou teorias combinadas visa-se atingir não necessariamente um preço, mas uma região de preço para o Ativo em questão.

Os possíveis métodos de avaliação de empresas devem ser sempre utilizados, com intuito informativo, para que gestores e investidores possam obter um panorama da instituição analisada, tomando assim decisões que contribuam para a administração de seus ativos. (TITMAN E MARTINS, 2010).

\subsubsection{Objetivos da avaliação de empresas}

Gestores, que buscam um alto grau de excelência na gestão de suas empresas, tendem a se cercar do máximo de informações necessárias sobre seu ramo de atividade. (ZDANOWICZ, 2012).

Damodaram (1997, p. 3), destaca que, "o papel da avaliação de empresa depende do objetivo que se tem em avaliar a instituição". Os principais motivadores de sua utilização são a avaliação e gestão de carteiras de ações, análise para aquisições de empresas e avaliações nas finanças corporativas.

Ainda segundo Damodaran (1997, p. 3);

Outro mito da avaliação de empresas é que uma avaliação bem pesquisa será eterna. Uma avaliação é feita com base em informações específicas da empresa e do mercado. Como 
consequência, ao surgirem novas informações relevantes, tais como, aumento ou diminuição de perspectiva futura do fluxo de caixa, o valor da empresa se modificará.

Logo, se percebe que os estudiosos sugerem aos analistas e gestores das empresas que se mantenha sempre uma continuidade, na aplicação de métodos de avaliação de empresas e suas análises de resultados auferidos.

\subsection{Conceito de Valuation}

Valuation é o termo em inglês para "avaliação de empresas", "valoração de empresas" e "arbitragem de valor". É área de finanças que estuda o processo de se avaliar o valor de determinada companhia. (PÓVOA, 2007).

Para Damodaran (1997, p. 17), a análise de investimento tem o papel de ignorar a teoria de investimento do "idiota maior", que sugere que o valor de um ativo é irrelevante até que encontre um "idiota maior" disposto a pagar por este ativo. Ainda segundo Damodaran (1997), "qualquer ativo, seja financeiro ou real, possui valor. A partir dessa afirmação pode-se entenderr que qualquer ativo pode ser avaliado utilizando as tradicionais e conhecidas técnicas de avaliação".

Com a precificação dos ativos se consegue determinar se a empresa obteve crescimento, se os gestores estão tendo êxito em suas decisões administrativas, auxiliando também em possíveis negociações quanto à venda, fusão e avaliação de seus gestores.

\subsubsection{Conceito, Objetivos e Limitações de Fluxo de Caixa}

O fluxo de caixa é uma forma de controle contábil de primeira necessidade, pois é com ele que se consegue fazer um diagnóstico preciso de uma empresa, analisando aspectos referentes a recebíveis, conta a pagar e a eventual necessidade de geração de caixa.

Para Assaf Neto (2008, p. 142), "os fluxos são as movimentações financeiras da companhia. As movimentações explicam de forma analítica, a variação no saldo de disponibilidade imediato, ou das aplicações financeiras da empresa". 
Zdanowicz (2012, p. 149), define o fluxo de caixa como; “técnica utilizada pelo executivo financeiro com o objetivo de apurar o total de ingressos e desembolsos financeiros da empresa para determinado momento, diagnosticando assim os excedentes ou a escassez de caixa, em função do nível desejado de caixa".

No atual nível de competitividade do mercado é imprescindível que se aplique e execute de forma correta e continua o fluxo de caixa na empresa seja ela grande média ou pequena.

Segundo Castilhos (2002, p. 56), "o fluxo de caixa livre é gerado pela empresa depois da dedução dos impostos, investimentos permanentes e variações esperadas no capital líquido". Este é diferente do controle de caixa tradicional pois fornece dados sobre o que de fato pode ser distribuído aos acionistas sem afetar as operações da empresa.

Por isso somente efetuando o controle das movimentações financeiras, se chegara a uma estimativa correta da capacidade de geração de lucro de uma empresa.

Com isso interpreta-se que o fluxo de caixa de uma empresa, tem como objetivo deixar clara e de fácil percepção o estado financeiro atual e futuro da instituição, oferecendo informações relevantes sobre as movimentações de entradas e saídas da mesma.

Segundo Zdanowicz (2012, p. 150), o principal objetivo do fluxo de caixa é projetar as entradas e saídas de recursos financeiros para um determinado período, visando calcular a necessidade em captar empréstimos e aplicar os recursos financeiros de modo seguro e adequado pela empresa.

Toda e qualquer empresa que objetiva um crescimento sustentável no longo prazo necessita implantar, organizar e gerenciar de forma constante o seu fluxo de caixa, pois é com o resultado do mesmo que se consegue observar como anda sua saúde financeira e se a mesma irá permanecer saudável no decorrer dos meses e anos subsequentes.

No entanto, quando determinada empresa não dá a importância para o seu fluxo de caixa, este pode ter limitações referentes à veracidade das informações.

Segundo Zdanowicz (2012, p. 162), "o fluxo de caixa pode apresentar algumas limitações, dependendo da forma como será elaborado e da importância que recebe dentro da empresa pela direção e pelos gerentes". A seguir, estão relacionados às limitações mais usuais segundo o autor citado a cima: 
a) não receber apoio integral da direção da empresa;

b) somente ser utilizado pela área financeira, não estar interligado com as demais áreas, gerando projeções incompletas e equivocadas na tomada de decisão;

c) distorção dos valores projetados por fatores internos e externos não previsíveis, acarretando prejuízos econômicos e financeiros;

d) os responsáveis pela elaboração não apresentam qualificação técnica suficiente.

Em síntese, a elaboração do fluxo de caixa não pode ter resistências internas, mas deve passar a ideia firme e forte de que todos dentro da empresa pensam em uma organização convergente para os objetivos e metas comuns.

Logo, as empresas deveriam implantar como estratégia competitiva uma cultura de controles financeiros bem elaborados, objetivando também, sinergia com os demais setores da organização, com isso seu planejamento e perspectivas sobre o cenário em que se encontra estaria mais correto, aumentando com isso seus lucros. (ZDANOWICZ, 2012).

\subsubsection{Conceito, Objetivos e Vantagens de Avaliação por Fluxo de Caixa Descontado}

O método de fluxo de caixa descontado é bastante aceito por administradores de empresas e investidores, pois possibilita diversas percepções de como se está a empresa no período analisado.

Assaf Neto (2006, p. 197) define fluxo de caixa descontado como método que, "representa o valor presente de fluxos de caixas futuros de um Ativo esperado pelo investidor, descontados a uma taxa que represente o seu custo de oportunidade".

Esse método é o mais usual pelos investidores, pois o mesmo segue os princípios básicos da Matemática Financeira, onde se leva em consideração o valor da capital financeiro no período de tempo analisado.

O método de fluxo de caixa descontado, fornece aos gestores e investidores informações precisas sobre o aspecto financeiro de uma empresa, demonstrando assim a capacidade da mesma de gerar lucro no cenário futuro. (ZDANOWICZ, 2012). 
A abordagem da avaliação por FCD fornece uma base para estimar o valor dos fluxos de caixa e, consequentemente, é pedra fundamental da análise financeira.

Segundo Copeland, Koller e Murrin (2002, p. 91), “os administradores que utilizam a abordagem do fluxo de caixa descontado na avaliação de empresas, buscando aumentar o fluxo de caixa livre, terão conseguido elevar o valor da ação". Seguindo a linha de pensamento dos autores citados acima, entende-se que as empresas que se valem desse método conseguem estimar um panorama futuro sobre suas movimentações financeiros, podendo assim se antecipar frente a possíveis cenários ruins.

Todo gestor que tem como objetivo gerar o desenvolvimento sustentável da empresa necessita se valer de informações que o método pode gerar, segundo Póvoa (2007), o fluxo de caixa descontado é o instrumento de precificação de ativos mais completo. Apesar das críticas com relação à precisão do modelo, sua proposta é proporcionar uma faixa de "valores justos" (considerando um risco e um retorno esperado) e não o "valor justo" exato.

Também segundo Zdanowicz (2012, p. 7), as principais vantagens para a empresa realizar as técnicas das análises relacionadas são:

a) determinar a lucratividade (margem) obtida e compará-la com o setor;

b) calcular o giro (rotação) dos produtos e/ou atividades no período;

c) apurar o retorno sobre o investimento total e próprio;

d) projetar a participação dos funcionários nos resultados;

e) conhecer os níveis mínimos e máximos de liquidez através de fluxo de caixa;

f) fixar um grau de endividamento aceitável;

g) ter o prévio conhecimento do ponto de equilíbrio das áreas e produtos;

h) adequar o capital de giro ao nível de atividade;

i) calcular quantos dias, em média, são necessários para financiar o ciclo operacional.

Portanto, o fluxo de caixa descontado fornece informações que possibilitam uma maior competitividade da empresa, onde o método é aplicado e gerenciado de forma constante. 


\subsubsection{Conceito de Avaliação Relativa ou Avaliação por Múltiplos}

Existem vários formas de precificação de empresas ou ativos financeiros, para abrirmos um pouco mais o assunto cita-se também a Avaliação por Múlltiplos, neste método de avaliação de empresas se busca uma comparação entre empresas de mesmo setor.

Segundo Damodaran (1997), o valor de um Ativo deriva da precificação de ativos "comparativos", padronizados pelo uso de uma variável comum.

Neste modelo de avaliação, Damodaran (1997, P. 17), nos coloca que, “as variáveis comuns podem ser lucros, fluxos de caixa, valores contábeis ou receitas. $\mathrm{O}$ autor refere-se a empresas analisadas e comparadas entre si quando tão somente é equivalente". O conceito visa encontrar ativos financeiros que estejam a um preço baixo ou mais elevado comparativamente aos seus concorrentes.

Segundo Damodaran (1994, p. 32) “a maior vantagem dos múltiplos é a simplicidade de cálculo, porém a análise deve ser criteriosa, observando todas as categorias (liquidez, endividamento, valor contábil etc.)"; para que assim os analistas tenham a visão do todo e evitem interpretações distorcidas do estado financeiro da empresa que estiverem analisando.

O método de avaliação relativa é utilizado por investidores por possibilitar uma análise mais simples, obtendo-se assim uma perspectiva de quais empresas de mesmo setor estão com as melhores oportunidades, estimando ativos que estejam baratos ou caros em relação a seus similares precificados pelo mercado no momento da análise.

\section{METODOLOGIA}

A metodologia utilizada no desenvolvimento do trabalho consiste em um estudo de casos múltiplos, que aborda métodos quantitativos e aplicação do método de avaliação de empresas por fluxo de caixa descontado.

O método adotado foi aplicado na empresa Anhanguera Participações S/A e Kroton Educacional S/A, com base nos dados financeiros encontrados nos sites institucionais das referidas empresas bem como no site da Bovespa, o período da análise referisse aos resultados financeiros dos anos de 2012 a 2014, por fim o estudo ocorreu seguindo os seguintes passos: 
1) Análise do histórico de desempenho: comparando os principais dados financeiros, tais como, Ebit, Ebitda, dívida, faturamento e lucro. Os dados analisados referem-se ao período de 2011 ao primeiro trimestre de 2014, foram estudados os Demonstrativos de Resultados de Exercícios e Balanços Patrimoniais das empresas;

2) Projeções de desempenho futuro: para as estimativas levou-se em conta as informações do que diz respeito a dados macroeconômicos, além disso para se estimar o valor presente pelo enfoque da empresa, este fez-se através dos fluxos de caixa esperados, descontados pelo custo médio ponderado do capital (WACC). Para este, aplicou-se o cálculo pela formula descrita a seguir.

$$
\mathrm{VPL}=\sum_{\mathrm{t}=1}^{\mathrm{t}=\infty} \frac{\mathrm{FCe}}{(1+\mathrm{WACC})^{\mathrm{t}}}
$$

Onde:

$\mathrm{VPL}=$ Valor presente líquido

$\mathrm{FCe}=$ Fluxo de caixa da empresa no período $\mathrm{t}$

WACC $=$ Custo médio de capital ponderado (Weighted Average costof capital).

As projeções são atribuídas ao fluxo de caixa livre, que contém informações referentes a custos, receitas, capital de giro, despesas, investimentos e impostos;

3) Estimativa do custo do capital: para calcular o custo do capital das empresas, foi aplicado o conceito do custo médio ponderado de capital (WACC), para este, o cálculo atribuído foi o seguinte:

$$
W A C C=K p l[P L /(P L+D)]+K d[D / P L+D)]
$$

Onde:

$\mathrm{Kpl}=$ Custo do patrimônio líquido

$\mathrm{Kd}=$ Custo da dívida após impostos

$\mathrm{PL}=$ Patrimônio líquido a valor de mercado

$\mathrm{D}=$ Dívida a valor de mercado 
O mesmo demonstra o capital próprio ponderado e o custo da dívida das empresas.

Para a taxa livre de risco do investimento foi utilizado o retorno equivalente aos títulos do tesouro direto do Governo Brasileiro em NTN-F pré-fixados, atrelados à taxa SELIC em um prazo de 5 anos;

4) Estimativa do valor da perpetuidade: para a obtenção da taxa de perpetuidade, utilizaram-se a formula descrita abaixo:

$$
\text { VPL perp. }=\sum_{i=0}^{\infty} F D_{i}=\sum_{i=0}^{\infty} \frac{F N}{(1+t)} \times\left(\frac{1+g}{1+t}\right)^{i}
$$

Onde:

VPLperp $=$ Valor presente líquido na perpetuidade

$\mathrm{i}=$ Taxa

$\mathrm{FD}=$ Fluxo de caixa descontado

$\mathrm{FN}=$ Fluxo de caixa nominal

$\mathrm{g}=$ Taxa de crescimento linear e continua

$\mathrm{t}=$ Valor do dinheiro no tempo

5) Cálculo dos resultados: tendo feito as projeções dos fluxos de caixa das empresas e determinado o custo médio ponderado do capital, buscou-se então calcular o preço alvo para as ações das empresas, os preços estimados, são encontrados com a projeção dos fluxos de caixa descontados a taxa livre de risco determinada, trazendo então ao valor presente do fluxo de caixa, após isso se dividiu o valor encontrado pelo número de ações das empresas estudadas.

Com isso se estabelece que o presente trabalho buscou informações correspondentes às movimentações financeiras das empresas no qual se aplicou o método de avaliação por fluxo de caixa descontado. Após isso, realizou-se uma análise comparativa das empresas, expondo-se as conclusões quanto suas capacidades de geração de riqueza do ponto de vista de investidores.

6) Interpretação dos resultados

Depois de feita as projeções e análises necessárias foram obtidos os preços alvos das ações das empresas estudadas, as considerações dadas 
para as ações foram feitas baseando-se no padrão utilizado pelo mercado como visto abaixo:

Compra - para recomendações de médio e longo prazo;

Manutenção - para manutenção da carteira das ações da empresa (neutra);

Venda - para recomendações desfavoráveis a empresa.

Também foi analisada a sensibilidade do crescimento com à perpetuidade estimada em $4,5 \%$ a $7,5 \%$. E, por final, verificou-se o preço justo das ações das empresas estudadas, visando saber se os investidores estão pagando caro ou barato pelas ações.

\section{RESULTADOS}

\subsection{Análise da empresa Anhanguera}

Em relação às projeções de receitas da empresa Anhanguera, chegou-se a um crescimento no fluxo de caixa após investimentos, da empresa Anhanguera de 31,4\% ao ano, para os próximos cinco anos, já sobre o cálculo de fluxo de caixa, somou-se depreciação sobre o Ebit, menos os impostos de renda e contribuição social, menos variação do capital circulante líquido e menos os investimentos permanentes. O imposto de renda e contribuição social variação do capital circulante líquido e os investimentos permanentes foram projetados com base nas estimativas projetadas para o setor. A seguir o Demonstrativo do Fluxo de Caixa da Anhanguera:

Quadro 1: Fluxo de caixa da Anhanguera Educacional Participações

\begin{tabular}{|c|c|c|c|c|c|}
\hline $\begin{array}{l}\text { Demonstração do Fluxo } \\
\text { de Caixa } \\
\text { Valores em milhões e } \\
\text { bilhões de reais }(k)\end{array}$ & $\begin{array}{l}30 / 06 / 2014 \\
(6 \mathrm{~m})\end{array}$ & $\begin{array}{l}\text { AH (\%) } \\
30 / 06 / 2013\end{array}$ & $\begin{array}{l}\text { AH (\%) } \\
30 / 06 / 2012\end{array}$ & $\begin{array}{l}30 / 06 / 2013 \\
(6 \mathrm{~m})\end{array}$ & $\begin{array}{l}30 / 06 / 2012 \\
(6 \mathrm{~m})\end{array}$ \\
\hline $\begin{array}{l}\text { Caixa Líquido Atividades } \\
\text { Operacionais }\end{array}$ & $56.587,0 \mathrm{k}$ & $-1.205,2 \%$ & $137,1 \%$ & $-5.120,0 \mathrm{k}$ & $23.863,0 \mathrm{k}$ \\
\hline $\begin{array}{l}\text { Caixa Gerado nas } \\
\text { Operações }\end{array}$ & $-9.122,0 \mathrm{k}$ & $-226,4 \%$ & $-135,0 \%$ & $7.219,0 \mathrm{k}$ & $26.091,0 \mathrm{k}$ \\
\hline $\begin{array}{l}\text { Variações nos Ativos e } \\
\text { Passivos }\end{array}$ & $65.709,0 \mathrm{k}$ & $-632,5 \%$ & $-3.049,2 \%$ & $-12.339,0 \mathrm{k}$ & $-2.228,0 \mathrm{k}$ \\
\hline
\end{tabular}




\begin{tabular}{|c|c|c|c|c|c|}
\hline $\begin{array}{l}\text { Demonstração do Fluxo } \\
\text { de Caixa } \\
\text { Valores em milhões e } \\
\text { bilhões de reais (k) }\end{array}$ & $\begin{array}{l}30 / 06 / 2014 \\
(6 \mathrm{~m})\end{array}$ & $\begin{array}{l}\text { AH (\%) } \\
30 / 06 / 2013\end{array}$ & $\begin{array}{l}\text { AH (\%) } \\
30 / 06 / 2012\end{array}$ & $\begin{array}{l}30 / 06 / 2013 \\
(6 \mathrm{~m})\end{array}$ & $\begin{array}{l}30 / 06 / 2012 \\
(6 \mathrm{~m})\end{array}$ \\
\hline Outros & $0,0 \mathrm{k}$ & - & - & $0,0 \mathrm{k}$ & $0,0 \mathrm{k}$ \\
\hline $\begin{array}{l}\text { Caixa Líquido Atividades } \\
\text { de Investimento }\end{array}$ & $-15.862,0 \mathrm{k}$ & $5,9 \%$ & $-86,0 \%$ & $-14.978,0 \mathrm{k}$ & $-112.977,0 \mathrm{k}$ \\
\hline $\begin{array}{l}\text { Caixa Líquido Atividades } \\
\text { de Financiamento }\end{array}$ & $-57.128,0 \mathrm{k}$ & $43,3 \%$ & $-645,8 \%$ & $-39.871,0 \mathrm{k}$ & $10.466,0 \mathrm{k}$ \\
\hline $\begin{array}{l}\text { Variação Cambial s/ } \\
\text { Caixa e Equivalentes }\end{array}$ & $0,0 \mathrm{k}$ & - & - & $0,0 \mathrm{k}$ & $0,0 \mathrm{k}$ \\
\hline $\begin{array}{l}\text { Aumento (Redução) de } \\
\text { Caixa e Equivalentes }\end{array}$ & $-16.403,0 \mathrm{k}$ & $-72,6 \%$ & $-79,1 \%$ & $-59.969,0 \mathrm{k}$ & $-78.648,0 \mathrm{k}$ \\
\hline $\begin{array}{l}\text { Saldo Inicial de Caixa e } \\
\text { Equivalentes }\end{array}$ & $18.690,0 \mathrm{k}$ & $-92,0 \%$ & $-92,2 \%$ & $233.720,0 \mathrm{k}$ & $240.690,0 \mathrm{k}$ \\
\hline $\begin{array}{l}\text { Saldo Final de Caixa e } \\
\text { Equivalentes }\end{array}$ & $2.287,0 \mathrm{k}$ & $-98,7 \%$ & $-98,6 \%$ & $173.751,0 \mathrm{k}$ & $162.042,0 \mathrm{k}$ \\
\hline Critério de consolidação & $\begin{array}{l}\text { Individuali- } \\
\text { zada }\end{array}$ & $\begin{array}{l}\text { Individuali- } \\
\text { zada }\end{array}$ & $\begin{array}{l}\text { Individuali- } \\
\text { zada }\end{array}$ & $\begin{array}{l}\text { Individuali- } \\
\text { zada }\end{array}$ & \begin{tabular}{|l} 
Individuali- \\
zada
\end{tabular} \\
\hline Critério de elaboração & IFRS & IFRS & IFRS & IFRS & IFRS \\
\hline
\end{tabular}

Fonte: Elaboração partir dos dados do site econoinfo (2014)

Com relação ao cálculo do custo de capital da Anhanguera Educacional Participações, utilizou-se o conceito de custo médio ponderado de capital (WACC). Copeland (2002, p. 205), afirma que, “o custo médio ponderado do capital é a taxa de desconto, ou o valor do dinheiro no tempo, usada para converter o fluxo de caixa livre em valor presente para todos os investidores". Já para a taxa livre de risco, foi usado como critério o retorno dos títulos do Tesouro Direto do Governo Brasileiro em NTN-F pré-fixados, com relação ao prêmio para o investimento em Bolsa de Valores usados foi, $6 \%$ acima da taxa livre de risco. E, por fim, para finalizar o cálculo do custo de capital próprio, deve-se inserir o beta no modelo. $O$ beta é avaliado pela volatilidade e o risco de determinado ativo financeiro. Encontrou-se beta 1,0. O resultado do custo médio ponderado, e do custo de capital próprio está disposto no quadro 2 . 
Quadro 2: Resultados de WACC da Anhanguera

\begin{tabular}{|l|l|}
\hline WACC & \\
\hline Contribuição do Capital Próprio & $11 \%$ \\
\hline Contribuição da Dívida & $0,00 \%$ \\
\hline WACC & $11 \%$ \\
\hline
\end{tabular}

Fonte: Elaboração a partir dos dados da pesquisa

Para se determinar o preço justo, utiliza-se o custo médio ponderado de capital (WACC) e o cálculo do fluxo de caixa da empresa, o próximo passo foi calcular o preço justo por ação. O preço justo é encontrado com o somatório dos fluxos de caixa futuros da companhia descontado pelo WACC, acrescentado da perpetuidade menos a dívida líquida. $\mathrm{O}$ valor encontrado representa o valor estimado da empresa, que deve ser dividido pelo número de ações para chegar ao preço justo.

A perpetuidade encontrada foi de $6 \%$, para o cálculo de perpetuidade, foi usado o fluxo de caixa do ano de 2014 acrescido a taxa de crescimento na perpetuidade. $\mathrm{O}$ resumo do fluxo de caixa descontado observa-se no quadro 3:

Quadro 3: Resultados do preço alvo da Anhanguera

\begin{tabular}{|l|l|}
\hline Perpetuidade & $6 \%$ \\
\hline Soma FCD & $\mathrm{R} \$ 1.805 \mathrm{~B}$ \\
\hline Valor na perpetuidade & $\mathrm{R} \$ 6.214 \mathrm{~B}$ \\
\hline Valor da Empresa & $\mathrm{R} \$ 8.019 \mathrm{~B}$ \\
\hline Dívida Líquida & $\mathrm{R} \$ 430.570 .000,00$ \\
\hline Participações & $\mathrm{R} \$-$ \\
\hline Valor Econômico da Empresa & $\mathrm{R} \$ 8.450 \mathrm{~B}$ \\
\hline Número de ações & $437,07 \mathrm{M}$ \\
\hline Preço Justo & $\mathrm{R} \$ 18,34$ \\
\hline Preço Alvo & $\mathrm{R} \$ 24,54$ \\
\hline Preço Atual & $\mathrm{R} \$ 18,35$ \\
\hline Potencial de Valorização & $34 \%$ \\
\hline
\end{tabular}

*em milhões e bilhões de reais.

Fonte: Elaboração própria a partir dos dados da pesquisa 
De acordo com o método aplicado, chegou-se ao valor por ação da Anhanguera de $\mathrm{R} \$ 18,34$, seu preço alvo ficou em $\mathrm{R} \$ 24,54$ frente ao fechamento do dia 31 de setembro, R\$ 18,35 por ação, isso representa um potencial de valorização de $34 \%$, em uma perspectiva de cinco anos, em relação ao dia 30 de setembro de 2014.

Assim, conforme a análise efetuada, a recomendação é de VENDA, para as ações da Anhanguera AEDU3. Pelo fato de que apesar da perspectiva ser que as ações tendem a se valorizar nos períodos futuros, esta valorização ficou estimada abaixo do valor da perpetuidade atribuída que é de $6 \%$ acima da inflação.

Por fim realizou-se o cálculo da sensibilidade da empresa anhanguera que tem como objetivo avaliar o efeito causado no preço alvo da empresa em diversas combinações de WACC e taxa de crescimento na perpetuidade. $\mathrm{Na}$ tabela de sensibilidade disposta abaixo, variou-se o custo de capital de $9,5 \%$ a $12,5 \%$ e a taxa de crescimento de $4,5 \%$ a $7,5 \%$.

Através da figura é possível perceber que o preço alvo varia conforme a combinação atribuída.

Figura 1: Análise de sensibilidade da empresa Anhanguera

PERPETUIDADE

\begin{tabular}{|l|l|l|l|l|l|l|l|l|}
\hline & $\mathbf{4 , 5 0} \%$ & $\mathbf{5 , 0 0 \%}$ & $\mathbf{5 , 5 0 \%}$ & $\mathbf{6 , 0 0 \%}$ & $\mathbf{6 , 5 0 \%}$ & $\mathbf{7 , 0 0 \%}$ & $\mathbf{7 , 5 0 \%}$ \\
\hline \multirow{4}{*}{ WACC } & 27,9 & 30,47 & 33,68 & $\mathbf{3 7 , 8 1}$ & 43,31 & 51,01 & 62,56 \\
\cline { 2 - 9 } & $\mathbf{1 0 , 0 0} \%$ & 24,94 & 26,96 & 29,44 & $\mathbf{3 2 , 5 3}$ & 36,51 & 41,82 & 49,24 \\
\cline { 2 - 9 } & $\mathbf{1 0 , 5 0 \%}$ & 22,48 & 24,11 & 26,06 & $\mathbf{2 8 , 4 5}$ & 31,43 & 35,27 & 40,39 \\
\cline { 2 - 9 } & $\mathbf{1 1 , 0 0 \%}$ & $\mathbf{2 0 , 4 1}$ & $\mathbf{2 1 , 7 4}$ & $\mathbf{2 3 , 3 1}$ & $\mathbf{2 4 , 5 4}$ & $\mathbf{2 7 , 5}$ & $\mathbf{3 0 , 3 8}$ & $\mathbf{3 4 , 0 8}$ \\
\cline { 2 - 9 } & $\mathbf{1 1 , 5 0 \%}$ & 18,65 & 19,75 & 21,03 & $\mathbf{2 2 , 5 4}$ & 24,36 & 26,58 & 29,36 \\
\hline $\mathbf{1 2 , 0 0} \%$ & 17,13 & 18,05 & 19,11 & $\mathbf{2 0 , 3 4}$ & 21,81 & 23,56 & 25,70 \\
\hline $\mathbf{1 2 , 5 0} \%$ & 15,81 & 16,58 & 17,47 & $\mathbf{1 8 , 4 9}$ & 19,69 & 21,1 & 22,79 \\
\hline
\end{tabular}

Fonte: Elaboração própria a partir dos dados da pesquisa

\subsection{Análise da empresa Kroton}

Em relação às projeções e receitas da Kroton, estima-se um crescimento no fluxo de caixa para a Kroton Educacional S/A de, 37\%, ao ano para os próximos cinco anos, com relação ao cálculo de fluxo de caixa. $\mathrm{O}$ cresci- 
mento da depreciação foi estimada conforme média histórica da empresa. O imposto de renda e contribuição social, a variação do capital circulante líquido e os investimentos permanentes foram projetados com base nas estimativas do mercado. A seguir, estão expostos o Demonstrativo do Fluxo de Caixa livre da Kronton.

Quadro 4: Fluxo de caixa da Kroton Educacional S/A

\begin{tabular}{|c|c|c|c|c|c|}
\hline $\begin{array}{l}\text { Demonstração do } \\
\text { Fluxo de Caixa } \\
\text { valores em milhões e } \\
\text { bilhões de reais }(k)\end{array}$ & $\begin{array}{l}31 / 12 / 2013 \\
(12 \mathrm{~m})\end{array}$ & $\begin{array}{l}\text { AH (\%) } \\
31 / 12 / 2012\end{array}$ & $\begin{array}{l}\text { AH (\%) } \\
31 / 12 / 2011\end{array}$ & $\begin{array}{l}31 / 12 / 2012 \\
(12 \mathrm{~m})\end{array}$ & $\begin{array}{l}31 / 12 / 2011 \\
(12 \mathrm{~m})\end{array}$ \\
\hline $\begin{array}{l}\text { Caixa Líquido } \\
\text { Atividades Operacionais }\end{array}$ & $559.596,0 \mathrm{k}$ & $78,1 \%$ & $-3.504,7 \%$ & $314.151,0 \mathrm{k}$ & $-16.436,0 \mathrm{k}$ \\
\hline $\begin{array}{l}\text { Caixa Gerado nas } \\
\text { Operações }\end{array}$ & $802.494,0 \mathrm{k}$ & $89,6 \%$ & $535,6 \%$ & $423.296,0 \mathrm{k}$ & $126.250,0 \mathrm{k}$ \\
\hline $\begin{array}{l}\text { Variações nos Ativos e } \\
\text { Passivos }\end{array}$ & $-169.856,0 \mathrm{k}$ & $357,6 \%$ & $27,9 \%$ & $-37.121,0 \mathrm{k}$ & $-132.828,0 \mathrm{k}$ \\
\hline Outros & $-73.042,0 \mathrm{k}$ & $1,4 \%$ & $640,9 \%$ & $-72.024,0 \mathrm{k}$ & $-9.858,0 \mathrm{k}$ \\
\hline $\begin{array}{l}\text { Caixa Líquido } \\
\text { Atividades de } \\
\text { Investimento }\end{array}$ & $-175.286,0 \mathrm{k}$ & $-78,9 \%$ & $-74,2 \%$ & $-831.309,0 \mathrm{k}$ & $-678.361,0 \mathrm{k}$ \\
\hline $\begin{array}{l}\text { Caixa Líquido } \\
\text { Atividades de } \\
\text { Financiamento }\end{array}$ & $-180.998,0 \mathrm{k}$ & $-131,1 \%$ & $-122,1 \%$ & $581.431,0 \mathrm{k}$ & $819.976,0 \mathrm{k}$ \\
\hline $\begin{array}{l}\text { Variação Cambial s/ } \\
\text { Caixa e Equivalentes }\end{array}$ & $0,0 \mathrm{k}$ & - & - & $0,0 \mathrm{k}$ & $0,0 \mathrm{k}$ \\
\hline $\begin{array}{l}\text { Aumento (Redução) de } \\
\text { Caixa e Equivalentes }\end{array}$ & $203.312,0 \mathrm{k}$ & $216,3 \%$ & $62,4 \%$ & $64.273,0 \mathrm{k}$ & $125.179,0 \mathrm{k}$ \\
\hline $\begin{array}{l}\text { Saldo Inicial de Caixa e } \\
\text { Equivalentes }\end{array}$ & $215.620,0 \mathrm{k}$ & $42,5 \%$ & $724,0 \%$ & $151.347,0 \mathrm{k}$ & $26.168,0 \mathrm{k}$ \\
\hline $\begin{array}{l}\text { Saldo Final de Caixa e } \\
\text { Equivalentes }\end{array}$ & $418.932,0 \mathrm{k}$ & $94,3 \%$ & $176,8 \%$ & $215.620,0 \mathrm{k}$ & $151.347,0 \mathrm{k}$ \\
\hline $\begin{array}{l}\text { Critério de } \\
\text { consolidação }\end{array}$ & $\begin{array}{l}\text { Consolida- } \\
d a\end{array}$ & $\begin{array}{l}\text { Consolida- } \\
d a\end{array}$ & $\begin{array}{l}\text { Consolida- } \\
d a\end{array}$ & $\begin{array}{l}\text { Consolida- } \\
d a\end{array}$ & $\begin{array}{l}\text { Consolida- } \\
d a\end{array}$ \\
\hline Critério de elaboração & IFRS & IFRS & IFRS & IFRS & IFRS \\
\hline
\end{tabular}

Fonte: Elaboração a partir do site econoinfo (2014)

Para o cálculo do custo de capital da Kronton Educacional SA, aplicouse o método de custo médio ponderado de capital (WACC). Para a taxa livre de risco e o prêmio estimado, também foram utilizados os mesmos critérios 
atribuídos a Anhanguera Educacional Participações SA. Por fim, para realizar o cálculo do custo de capital próprio, insere-se o beta no modelo, com isso conforme resultados encontrados utilizou-se beta, 1,0. Abaixo, segue quadro com os dados obtidos.

Quadro 5: Resultados de WACC da Kroton idem

\begin{tabular}{|l|l|}
\hline WACC & \\
\hline Contribuição do Capital Próprio & $11 \%$ \\
\hline Contribuição da Dívida & $0,00 \%$ \\
\hline WACC & $11 \%$ \\
\hline
\end{tabular}

Fonte: Elaboração própria a partir dos dados da pesquisa

No preço justo utiliza-se o custo médio ponderado de capital (WACC) e o cálculo do fluxo de caixa da empresa, busca-se então o preço justo por ação. O preço justo é encontrado com o somatório dos fluxos de caixa futuros da companhia descontado pelo WACC, acrescentado da perpetuidade menos a dívida líquida. $\mathrm{O}$ valor encontrado representa o valor estimado da empresa, que deve ser dividido pelo número de ações para chegar ao preço justo.

A perpetuidade atribuída foi de $6 \%$, pelo fato de que o mercado financeiro possui uma grande perspectiva sobre o potencial de crescimento do setor. Para o cálculo de perpetuidade, foi usado o fluxo de caixa do ano, que é o fluxo de 2014 acrescido a taxa de crescimento na perpetuidade. $\mathrm{O}$ resumo do fluxo de caixa descontado segue abaixo:

Quadro 6: Resultados do preço justo da Kroton

\begin{tabular}{|l|l|}
\hline Perpetuidade & $6 \%$ \\
\hline Soma FCD & $\mathrm{R} \$ 4.265 \mathrm{~B}$ \\
\hline Valor na perpetuidade & $\mathrm{R} \$ 14.690 \mathrm{~B}$ \\
\hline Valor da Empresa & $\mathrm{R} \$ 18.955 \mathrm{~B}$ \\
\hline Dívida Líquida & $\mathrm{R} \$ 544.080 .000,00$ \\
\hline Participações & $\mathrm{R} \$-$ \\
\hline Valor Econômico da Empresa & $\mathrm{R} \$ 19,500 \mathrm{~B}$ \\
\hline Número de ações & $268,70 \mathrm{M}$ \\
\hline
\end{tabular}




\begin{tabular}{|l|l|}
\hline Perpetuidade & $6 \%$ \\
\hline Preço Justo & $\mathrm{R} \$ 70,54$ \\
\hline Preço Alvo & $\mathrm{R} \$ 94,40$ \\
\hline Preço Atual & $\mathrm{R} \$ 15,38$ \\
\hline Potencial de Valorização & $513 \%$ \\
\hline
\end{tabular}

*em milhões e bilhões de reais.

Fonte: Elaboração própria a partir dos dados da pesquisa

De acordo com o método aplicado, chegou-se ao valor por ação da Kroton de $\mathrm{R} \$ 70,54$, e o preço alvo de $\mathrm{R} \$ 94,40$, frente ao preço de fechamento do pregão do dia 30 de setembro de 2014, R \$15,38, por ação. Isso representa um potencial de valorização de $513 \%$, em relação ao preço de fechamento do último pregão analisado. Assim, conforme a análise efetuada, a recomendação é de COMPRA, para as ações da Kroton Educacional $\mathrm{S} / \mathrm{A}$ KROT3, pelo fato de que a perspectiva é que as ações tendem a sofrer valorização.

A análise de sensibilidade tem como objetivo demonstrar o efeito causado no preço alvo da empresa, utilizando-se combinações de WACC e taxa de crescimento na perpetuidade, conforme figura apresentada abaixo a variação do custo de capital foi de $9,50 \%$ a $12,50 \%$ e a taxa de crescimento de $4,5 \%$ a $7,5 \%$.

Figura 2: Análise de sensibilidade da Kroton

PERPETUIDADE

WACC

\begin{tabular}{|l|l|l|l|l|l|l|l|}
\hline & $\mathbf{4 , 5 0 \%}$ & $\mathbf{5 , 0 0 \%}$ & $\mathbf{5 , 5 0 \%}$ & $\mathbf{6 , 0 0 \%}$ & $\mathbf{6 , 5 0 \%}$ & $\mathbf{7 , 0 0 \%}$ & $\mathbf{7 , 5 0 \%}$ \\
\hline $\mathbf{9 , 5 0 \%}$ & 104,53 & 115,5 & 129,22 & $\mathbf{1 4 6 , 8 5}$ & 170,36 & 203,28 & 252,65 \\
\hline $\mathbf{1 0 , 0 0 \%}$ & 93,85 & 102,67 & 113,44 & $\mathbf{1 2 6 , 9 1}$ & 144,22 & 167,31 & 199,63 \\
\hline $\mathbf{1 0 , 5 0 \%}$ & 84,97 & 92,19 & 100,84 & $\mathbf{1 1 1 , 4 2}$ & 124,65 & 141,65 & 164,33 \\
\hline $\mathbf{1 1 , 0 0 \%}$ & $\mathbf{7 7 , 4 8}$ & $\mathbf{8 3 , 4 7}$ & $\mathbf{9 0 , 5 6}$ & $\mathbf{9 4 , 4 0}$ & $\mathbf{1 0 9 , 4 5}$ & $\mathbf{1 2 2 , 4 4}$ & $\mathbf{1 3 9 , 1 4}$ \\
\hline $\mathbf{1 1 , 5 0 \%}$ & 71,07 & 76,12 & 82,01 & $\mathbf{8 8 , 9 7}$ & 97,32 & 107,52 & 120,28 \\
\hline $\mathbf{1 2 , 0 0 \%}$ & 65,54 & 69,84 & 74,79 & $\mathbf{8 0 , 5 8}$ & 87,41 & 95,61 & 105,64 \\
\hline $\mathbf{1 2 , 5 0 \%}$ & 60,71 & 64,4 & 68,62 & $\mathbf{7 3 , 4 9}$ & 79,18 & 85,89 & 93,95 \\
\hline
\end{tabular}

Fonte: Elaboração própria a partir dos dados da pesquisa 
Através da figura 2, é possível perceber conforme está disposto os resultados da análise de sensibilidade da empresa Kroton, que o preço sofre certa volatilidade, conforme a combinação proposta.

\section{CONSIDERAÇÕES FINAIS}

A avaliação e precificação de uma empresa correspondem ao estudo e à interpretação das informações financeiras analisadas sobre a mesma, tendo como objetivo, chegar a um valor financeiro considerado justo.

Estas são de suma importância para a verificação do seu desempenho, pois demonstram a situação em que elas se encontram no presente momento, sobre o ponto de vista de investidores. Objetiva verificar a solidez e a capacidade da mesma manter um crescimento sustentável no longo prazo, assim como gerar uma perspectiva de retorno sobre o capital financeiro investido aos mesmos.

As informações encontradas podem e devem ser utilizadas para observar o seu desempenho e a capacidades de gerar riqueza no curto médio e longo prazo. Ressalta-se que de que todos os indicadores são relevantes no momento de se efetuar uma análise fundamentalista sobre a instituição analisada, pois se recomenda observar os fatores como endividamento, capacidade de gerar caixa, e potencial de escalabilidade do negócio em si.

Desta forma expõe-se que, o fluxo de caixa é um dos principais fatores que possam garantir a segurança e a continuidade do negócio, é fato fundamental que qualquer investimento financeiro deva gerar lucros, no aspecto de uma empresa, além disso, devesse também gerar caixa em suas atividades, pois é com este que se verifica disponibilidade para com seus compromissos assumidos. (PÓVOA. A 2007).

No decorrer deste artigo, percebeu-se que o estudo sobre avaliação de empresas é uma metodologia especializada e complexa que serve para orientar possíveis decisões de investidores. Assim, foi utilizada a metodologia do fluxo de caixa descontado. No desenvolvimento deste estudo, foi necessário, estimar crescimento de receitas, custos, despesas, entre outras inúmeras contas. A partir destas premissas, foi possível projetar os dados necessários para se analisar as empresas estudadas.

Percebe-se que o setor de educação superior tem um grande potencial de crescimento. Através desta monografia foi possível perceber que esse potencial se justifica em função da grande onda de incentivos a educação no país. 
As principais conclusões e recomendações sobre as empresas em análise no que tange aos preços alvos são:

Quadro 7: Análise do potencial de investimento

\begin{tabular}{|l|l|l|l|l|l|}
\hline Empresa & Código & Preço-alvo & $\begin{array}{l}\text { Fechamento } \\
\text { de 30/09/2014 }\end{array}$ & Potencial & Recomendação \\
\hline Anhanguera & AEDU3 & R\$ 24,54 & R\$ 18,35 & $34 \%$ & Venda \\
\hline Kroton & KROT3 & R\$ 94,40 & R $\$ 15,38$ & $513 \%$ & Compra \\
\hline
\end{tabular}

Fonte: Elaboração própria a partir dos dados da pesquisa

Conforme observa-se no quadro anterior, interpreta-se que a Anhanguera apresenta potencial de crescimento reduzido, se comparado à Kroton.

Segundo a análise alguns dos motivos para que isso ocorra é o fato de que a Kroton Educacional S/A, possui além dos centros de educação a distância, pólos presenciais, com cursos que geram maior fluxo de caixa para a instituição, como cursos de engenharia. Outro fator verificado é uma maior confiança do mercado na instituição, pois seu tamanho e capacidade de penetração no seu nicho de mercado tem sido superior a Anhanguera Participações S/A.

Com este trabalho acadêmico, foi possível suprir um pouco a falta de estudos desta área, tendo em vista que o artigo vai de encontro aos anseios da academia de proporcionar estudos científicos sobre como se realizar avaliação de valor de mercado de empresas dos mais diversos tipos trazendo também relatórios sobre as duas maiores empresas de educação listadas na bolsa no Brasil. Através desse trabalho realizou-se uma análise do valor das empresas, verificando se seus preços encontraram-se acima ou abaixo do preço negociado na Bovespa.

A elaboração deste trabalho foi de grande valor no sentido de fortalecer os estudos de empresas relativamente novas na bolsa de valores brasileira. Assim, o mesmo cumpriu com seu objetivo de apresentar um estudo elaborado das duas empresas focadas nesta área.

Com tudo o estudo realizado possui limitação Quanto a amostra pois utilizou-se apenas duas empresas para se fazer a comparação no que se refere a melhor opção de investimento sobre o nicho especifico estudado.

Além disso, existem diversas formas de se efetuar a precificação de uma empresa, utilizando-se também series temporais, modelos estatísticos, 
outros modelos financeiros como avaliação por múltiplos, já citados no decorrer do artigo, expectativas do mercado sobre a mesma entre outros.

Por fim sobre aspectos de continuidade referente ao estudo elaborado sugere-se utilizar um maior número de empresas do setor ampliando a análise para todas as instituições da BM\&FBOVESPA que tem como ramo de negócio o ensino, gerando assim mais assertividade do ponto de vista do melhor risco/retorno para possíveis investidores.

\title{
VALUATION APPLIED TO THE HIGHER EDUCATION SECTOR BY DISCOUNTED CASH FLOW
}

\begin{abstract}
This study aims to conduct the valuation of two publicly traded companies in the Higher Education sector in Brazil: Anhanguera Educacional Participações S/A, and Kroton Educacional S/A. The method used to achieve the proposed objective was the discounted cash flow, which corresponds to designing the future box, find the discount rate for projected cash flow, aiming to arrive at the fair value of the company. The analysis period corresponds the years 2010 to 2014. Finally, the financial results have shown that probability is that the company Kroton Educacional S/A gain advantage as the risk/return, with this in view the investment statement was to same.
\end{abstract}

Keywords: Valuation; Discounted cash flow; Evaluation; Accounting

JEL Classification: G1; G11

\section{REFERÊNCIAS}

ASSAF NETO, A. Finanças corporativas e valor. 3. ed. São Paulo: Atlas, 2008.

ASSAF NETO, A. Mercado financeiro. 7. ed. São Paulo: Atlas, 2006. 
CASTILHOS, V. F. Avaliação de uma empresa usando o método do fluxo de caixa descontado. 2002. 130p. Dissertação (Mestrado em Administração), Programa de Pós-Graduação em Administração, Escola de Administração, Universidade Federal do Rio Grande do Sul, Porto Alegre, 2002.

COPELAND, T.; KOLLER, T.; MURRIN, J. Avaliação de empresas valuation: calculando e gerenciando valor das empresas. 3. ed. São Paulo: Pearson Makron Books, 2002.

DAMODARAN, A. Avaliação de investimentos: ferramentas e técnicas para a determinação do valor de qualquer ativo. Rio de Janeiro: Qualitymark, 1997.

DAMODARAN, A. Damodaran on valuation: security analysis for investment and corporate finance. Estados Unidos: John Wiley e Sons, 1994.

FURASTÉ, P. A. Normas técnicas para o trabalho científico: explicitação das normas da ABNT. 16. ed. Porto Alegre: Dáctilo Plus, 2013.

Informações disponíveis em: < http://ri.kroton.com.br>. Acesso em: 04 jun. 2014.

Informações disponíveis em: $<\underline{\mathrm{http}}: / / \mathrm{www}$.anhanguera.com/ri $>$. Acesso em: 04 jun. 2014.

Informações disponíveis em: $<\underline{\mathrm{http}}$ ://www.econoinf.com.br $>$. Acesso em: 04 jun.2014.

PÓVOA, A. Valuation: como precificar ações. 2. ed. São Paulo: Globo, 2007.

TITMAN, S.; MARTIN, J. D. Avaliação de projetos e investimentos: valuation. 2. ed. Porto Alegre: Bookman, 2010.

ZDANOWICZ, J. E. Finanças aplicadas para empresas de sucesso. São Paulo: Atlas, 2012. 